may be conditioned by a number of factors, among which adherence could be crucial.

Objectives: The aim of this study is to explore adherence to MTX in patients with rheumatic diseases, facilitators and perceived when taking and maintaining the prescription.

Methods: A qualitative study of content analysis was performed. Focus groups with patients taking either oral or subcutaneous MTX (being the main or coadjuvant treatment) for any rheumatic disease was performed. The groups were moderated by a rheumatologist that was unknown for the patients. The speech was recorded and transcribed. Subsequently, an inductive coding was performed with the help of Atlas.ti and main themes and sub-themes were extracted, with examples of verbatim anonymized speech.

Results: Three focus groups were conducted, with a total of 12 participants, of whom eight were women, seven had rheumatoid arthritis, three had psoriatic arthritis, one had spondyloarthritis, and one had systemic lupus erythematosus. All patients reported an adequate adherence to treatment. The barriers identified were: information in the leaflet, technical language in the consults, difficult access to doctor's appointment, social environment, side effects and the subcutaneous device. As facilitators, the following aspects were discussed: good predisposition of the physician, reliable graphic information, role of associations and partners support.

The unmet needs detected were: problems with travelling, protocols for eventualities, absence of a plan of care, neglection of "non-physical" symptoms, disinformation on side effects and training in complementary aspects.

Conclusion: Getting reliable information was the main barrier identified. The environment and side effects may also negatively impact on adherence. Shared decision making is a goal to be achieved in the future in these patients.

Disclosure of Interests: Teresa Oton Consultant of: Novartis Farmaceutica, SA, Pfizer, S.L.U., Merck Sharp \& Dohme España, S.A., Roche Farma, S.A, Sanofi Aventis, AbbVie Spain, S.L.U., and Laboratorios Gebro Pharma, SA (All trhough institution), Loreto Carmona Grant/research support from: Novartis Farmaceutica, SA, Pfizer, S.L.U., Merck Sharp \& Dohme España, S.A., Roche Farma, S.A, Sanofi Aventis, AbbVie Spain, S.L.U., and Laboratorios Gebro Pharma, SA (All trhough institution), José Luis Andréu Sánchez: None declared DOI: 10.1136/annrheumdis-2020-eular.4059

\section{SAT0637-HPR IMPAIRED HEALTH-RELATED QUALITY OF LIFE AND PHYSICAL FUNCTION IN NORWEGIAN PATIENTS WITH TAKAYASU ARTERITIS.}

T. Garen ${ }^{1}, \varnothing$. Palm ${ }^{1}$, B. Gudbrandsson ${ }^{1} .{ }^{1}$ Oslo University Hospital, Oslo, Rheumatology, Oslo, Norway

Background: Takayasu arteritis (TAK) is a rare vasculitis of large vessels in young women. We have previously reported a point prevalence of $25.6 / 10^{6}$. The disease most prevalently limited to the aortic arch and its branches (Type 1) among North Europeans.

Early symptoms of TAK include fever, myalgia and loss of appetite. Later, the inflammation of blood vessel may lead to irreversible vascular damage and ischemic symptoms with claudication of the extremities. We have recently found that TAK may reduce life expectancy, mainly due to cardiovascular complications. The median age among those deceased was only 58 years. These findings clearly indicate that TAK may have severe impact on the wellbeing of the patients and their physical capacity.

It is widely accepted to include patients' perspectives related to their health condition and treatment to better understand the burden of the disease and the impact on their daily life activities. However, studies of health-related quality of life (HRQol) in TAK has rarely been undertaken, and we are not aware of any studies from the Northern part of Europe.

Objectives: (i)To compare HRQol in Norwegian TAK with age- and sex matched Norwegian normative data. (ii) To assess patients reported disease symptoms (iii). To evaluate the impact of disease symptoms on HRQol and functional status. Methods: Patients with TAK from "The Norwegian Systemic Connective Tissue Disease and Vasculitis Registry" (NOSVAR) were included. All patients had to fulfill the American College of Rheumatology classification criteria and/or the modified Ishikawa diagnostic criteria for TAK and return three sets of questionnaires: 1) The SF 36 was applied to measure HRQL. Age- and sex-matched normative data were obtained from a former study and consisted of 2471 randomly selected Norwegian citizens (1162 women) who were $>20$ yrs. of age. 2) Questions from the Modified Health Assessment Questionnaire (MHAQ). 3) Patients answered questionnaires regarding disease symptoms, employment and assessment of general health status Disease duration was defined as the time from diagnosis to date of registration. Pearson correlation tests were used to explore associations between disease symptoms and HRQL.

Results: A total of 33 female patients were included. Their mean age at diagnosis was $32 \mathrm{yrs}$. and they had a disease duration of median, 8,9 yrs. at inclusion. The SF-36 results adjusted for age, indicated significantly impaired HRQoL in the patients compared with normative data on 6 of eight subscales, with the largest differences observed for role physical (51 vs. $80, p<0.001$ ) and general health (51 vs. 78, p<0.001) (Fig. 1). Symptoms of claudication in legs correlated strongly to moderately with activities as running or jogging $3 \mathrm{~km}(.538, p<0.001)$, walking outdoor on flat ground $(.542, \mathrm{p}=0.002)$, climbing stairs $(.564, \mathrm{p}=0.001)$ and run errands and shop $(.417, p=0.016)$ assessed by MHAQ. The most frequently reported symptoms were dyspnea at physical exertion $(67 \%)$, claudication of arms $(63 \%)$ and myalgia (55\%). A moderate correlation was found between claudication of legs $(-.572, p<0.001)$, pain (VAS) $(-.585, p<0.001)$, fatigue $(-.493$ $\mathrm{P}<0.002)$, dyspnea $(-.471, \mathrm{p}<0.002)$ and physical function as reported in SF36. Similarly, a moderate negative correlation was present between pain (VAS) $(-.553, p<0.001)$, fatigue (VAS) $(-.482, p<0.002)$ and mental health in SF36. At the time of diagnosis, $89 \%$ were employed, compared to only $21 \%$ at registration. Patients self-perceived health status was reported in $39 \%$, compared to $79 \%$ in a share of the Norwegian population aged 16 or over (The data from the EU Statistics on Income and Living Condiions(EU SILC).

Conclusion: Patients with TAK reported reduced QoL compared to data from our general population. The most frequently reported disease symptoms were dyspnea at exertion, claudication of arms and myalgia. Pain, fatigue and dyspnea at exertion had a significant impact on HRQol. Claudication of legs correlated significantly with impaired walking activities reported in MHAQ.

Disclosure of Interests: None declared

DOI: 10.1136/annrheumdis-2020-eular.3595

\section{SAT0638-HPR CHARACTERIZING THE IMPACT OF AXIAL SPONDYLOARTHRITIS ON DAILY LIFE: GENDER AND PATIENT-REPORTED OUTCOMES ASSOCIATED WITH FUNCTIONAL LIMITATION IN CANADA. RESULTS FROM THE IMAS SURVEY}

P. Rahman ${ }^{1}$, M. Garrido-Cumbrera'2 , S. Rohekar ${ }^{3}$, M. Mallinson ${ }^{4}$, G. Major ${ }^{5}$, A. Jovaisas ${ }^{6}$, N. Haroon ${ }^{7}$, W. Gerhart ${ }^{8}$, A. J. Debrum Fernandes ${ }^{9}$, M. Cohen ${ }^{10}$, J. Chan ${ }^{11}$, P. Leclerc ${ }^{12}$, J. Schneiderman ${ }^{12}$, R. Inman ${ }^{7}{ }^{1}$ Memorial U., St. John's, Canada: ${ }^{2}$ U. de Sevilla, Sevilla, Spain; ${ }^{3}$ Western U., London, Canada; ${ }^{4}$ Patient, Toronto, Canada; ${ }^{5} \mathrm{CSA}$, Toronto, Canada; ${ }^{6} \mathrm{U}$. of Ottawa, Ottawa, Canada; ${ }^{7} \mathrm{TWH}$, Toronto, Canada; ${ }^{8} \mathrm{CSA}$, Phelpston, Canada; ${ }^{9} \mathrm{U}$. de Sherbrooke, Sherbrooke, Canada;

${ }^{10}$ MUHC, Montreal, Canada; ${ }^{11}$ UBC, Vancouver, Canada; ${ }^{12}$ Novartis, Montreal, Canada

Background: Understanding the most limiting daily activities reported by patients is important for a holistic healthcare approach.

Objectives: To evaluate the degree of functional limitation on daily activities and its association with PROs in Canada.

Methods: The International Map of Axial Spondyloarthritis (IMAS) is a cross-sectional online survey of non-selected patients with self-reported axSpA conducted in 22 countries and endorsed by the Axial Spondyloarthritis International Federation. IMAS captures the patients' perspective of the burden of axSpA. The Canadian adaptation included a review of the survey by an advisory board of axSpA patients and a national steering committee composed of the Canadian Spondylitis Association, rheumatologists and axSpA patients. Canadian participants were recruited from 2018 to 2019. Socio-demographics variables, BASDAl and mental health (GHQ-12) data were collected. Degree of functional limitation in 18 daily activities was evaluated using a 3-point Likert scale. Bivariate analysis was performed to assess activities associated with poorer BASDAI and mental health status.

Table 1. BASDAl and mental health (GHQ-12)- impact on daily activities $(\mathrm{N}=542)$

\begin{tabular}{|c|c|c|c|c|c|c|}
\hline & \multicolumn{3}{|c|}{$\begin{array}{c}\text { BASDAI } \\
\text { Mean } \pm \text { SD }\end{array}$} & \multicolumn{3}{|c|}{$\begin{array}{c}\text { GHQ-12 } \\
\text { Mean } \pm \text { SD }\end{array}$} \\
\hline & $\begin{array}{c}\text { Low } \\
\text { limitation }\end{array}$ & $\begin{array}{l}\text { Medium } \\
\text { + High } \\
\text { Limitation }\end{array}$ & p-value & $\begin{array}{c}\text { Low } \\
\text { limitation }\end{array}$ & $\begin{array}{c}\text { Medium } \\
\text { + High } \\
\text { Limitation }\end{array}$ & p-value \\
\hline $\begin{array}{l}\text { Dressing / } \\
\text { undressing }\end{array}$ & $5.5 \pm 2.0$ & $6.4 \pm 4.4$ & $<.001^{*}$ & $4.4 \pm 3.8$ & $5.7 \pm 4.0$ & $.007^{\star}$ \\
\hline $\begin{array}{l}\text { Washing / personal } \\
\text { grooming }\end{array}$ & $5.6 \pm 2.0$ & $6.3 \pm 2.0$ & $.002^{*}$ & $4.7 \pm 4.1$ & $5.6 \pm 4.1$ & .099 \\
\hline $\begin{array}{l}\text { Taking a bath / } \\
\text { shower }\end{array}$ & $5.6 \pm 2.0$ & $6.6 \pm 1.8$ & $<.001^{*}$ & $4.2 \pm 4.0$ & $5.9 \pm 4.0$ & $.002^{\star}$ \\
\hline Tying shoe laces & $5.4 \pm 2.0$ & $6.1 \pm 2.0$ & $.005^{\star}$ & $4.3 \pm 3.8$ & $5.2 \pm 4.1$ & $.044^{\star}$ \\
\hline $\begin{array}{l}\text { Walking / getting } \\
\text { around the house }\end{array}$ & $5.5 \pm 2.0$ & $6.4 \pm 1.9$ & $<.001^{\star}$ & $4.2 \pm 3.9$ & $5.6 \pm 4.1$ & $.005^{\star}$ \\
\hline Stair climbing & $5.1 \pm 1.9$ & $6.3 \pm 1.8$ & $<.001^{*}$ & $3.4 \pm 3.4$ & $5.4 \pm 4.0$ & $<.001^{\star}$ \\
\hline $\begin{array}{l}\text { Lying down / getting } \\
\text { up from bed }\end{array}$ & $5.2 \pm 2.0$ & $6.3 \pm 1.9$ & $<.001^{*}$ & $3.6 \pm 3.6$ & $5.5 \pm 4.1$ & $<.001^{*}$ \\
\hline Going to the toilet & $5.4 \pm 2.0$ & $6.7 \pm 1.9$ & $<.001^{\star}$ & $4.3 \pm 4.2$ & $5.6 \pm 3.9$ & $.024^{\star}$ \\
\hline Shopping & $5.6 \pm 1.8$ & $6.2 \pm 1.9$ & $.003^{\star}$ & $4.1 \pm 3.7$ & $5.3 \pm 4.1$ & $.025^{\star}$ \\
\hline Cooking & $5.6 \pm 1.9$ & $6.3 \pm 1.8$ & $.008^{\star}$ & $3.7 \pm 3.6$ & $5.8 \pm 4.2$ & $<.001^{*}$ \\
\hline Eating & $5.9 \pm 2.1$ & $6.9 \pm 1.9$ & $.024^{\star}$ & $5.0 \pm 4.4$ & $5.8 \pm 3.9$ & .282 \\
\hline $\begin{array}{l}\text { Housework / } \\
\text { cleaning }\end{array}$ & $4.9 \pm 2.0$ & $6.0 \pm 1.8$ & $<.001^{\star}$ & $3.7 \pm 3.6$ & $4.8 \pm 4.0$ & $.021^{\star}$ \\
\hline Walking down the & $5.4 \pm 1.9$ & $6.1 \pm 2.0$ & $.005^{\star}$ & $4.4 \pm 3.8$ & $5.1 \pm 4.1$ & .228 \\
\hline
\end{tabular}

